\title{
Computers in Education in Finland
}

\author{
Jari Koivisto \\ Principal, LUMO Upper Secondary School, Vantaa, Finland \\ jari.koivisto@vantaa.fi
}

\begin{abstract}
This chapter traces the history of computers in education in Finland from the early 1970 s to today. It begins by noting that the history of computers in education in Finland began in the early 70s after many Finnish companies and universities acquired and made use of mainframe computers. Some of the university students who used computers in their studies afterwards became teachers and brought with them the idea of using computers in classroom education in Finnish schools. At that time, however, most teachers could not see that a computer would have any practical significance in the classroom. The chapter goes on to examine the types of computer used in schools in the 70s and 80 s, the available software, networks, developments in curriculum and the future.
\end{abstract}

Keywords: Schools in Finland, ICT, programming, software, curriculum.

\section{$1 \quad$ Early Technology}

The history of using computers in education in Finland started in early 70s. Many Finnish companies and universities had already earlier acquired some mainframe UNIVAC and IBM computers to make their processes faster and more efficient. The students at the Technical University of Helsinki built their own ESKO computer during six years 1954 - 1960. For obvious reasons these computer services were not available for school education. Fortunately the university students could use the computers in their studies and many of those students became teachers afterwards. These people brought the idea of using computers in classroom education in Finnish schools. However at that time the general idea among the teachers was that during their active service in the school a computer will not have any practical significance in the classroom. In their mind the computers will be used in the national tax administration, insurance companies and finance.

By the end of 70s and in the beginning of 80s computer programming became increasingly popular hobby among the teachers who were allowed to use some computer-time using the university computers, and also among young people, mainly young men, who could afford to buy for themselves the first desktop computers like Commodore VIC-20, Apple II or Sinclair ZX81 machines. An important component in most of the home computers was the 8-bit Zilog 80 processor. It came into market in 1976 and it was exceptionally suitable to be used in affordable home computers. 
One of the curiosities in the Finnish education was the HP 65 programmable calculator which Hewlett-Packard introduced in 1974. It was a quite popular device among the technical university students, and a number of maths teachers adopted it to their daily work as well. It was very advanced at that time but using it was not so easy because its user interface was based on the reverse Polish notation (RPN) invented by Polish logician Jan Łukasiewicz. This calculation logic, and accordingly the user interface, was stack-based. This postfix notation made it complicated for the user to communicate correctly with the calculator. The same notation was also used in the FORTH programming language for its arithmetic operators. There were a number of FORTH enthusiasts among the Finnish maths teachers but the language was soon replaced by BASIC, Pascal and C languages.

The first real educational computer in Finland was the Swedish ABC-80 which came to Finland in the end of 70s. Many schools started their computer classes with ABC-80 but it was very exceptional to have a computer lab with a reasonable number of computers in the school. ABC-80 had some educational software and it was convenient for practicing BASIC-programming but otherwise it did not stand any chance against much more modern Nokia MikroMikko computers released in 1981.

The common operating system then was $\mathrm{CP} / \mathrm{M}$ and the most common programming language was BASIC. In many cases young computer enthusiasts were using assembly language because the computer memory was very limited. Commodore 64 home computer became a legend almost immediately when it was launched for Christmas season in 1982. It had a MOS Technology 6510 processor with an assembly language easy enough to be used by anybody who could spare some time to learn it. Programmers exchanged their codes actively and the publicly available software library increased in a fast speed.

The pioneers of assembly programming did not bring any significant added value to education then but their experience was valuable afterwards. Home computer programming expanded quite soon to a business, and an increasing collection of educational software was soon available both in commercial and freeware form.

Nokia computers occupied the computer labs in 80s in Finland. The collection of educational software was quite extensive and the computers could be connected as an educational network inside the school. This was the first opportunity for a regular teacher to start using computers in a productive way. A certain set of language teaching software applications became especially popular because they were easy and straightforward enough for a regular teacher and student to use. The pedagogical added value of the computer lab networks was questionable. On the other hand it was convenient for a teacher to secretly monitor what the students are up to but in practice only a very few of the teachers in reality used this option. In many cases the teachers used the network only to distribute task files to the students.

Some schools bought Apple Macintosh computers but these did not become very popular because of their high price. On the other hand Mac-machines opened the eyes for many teachers to see the real possibilities of computers in education. The graphical user interface was appealing to teachers who were not interested in programming or any technical tricks. They created a certain pressure to the local administrators to buy Apple, and in many cases the administrators agreed and bought Apple computers in spite of expenses. 
The Commodore 64 computer became a success in special needs education in Finland thanks to some really devoted Finnish special needs education teachers. The reason was that a significant number of those people who started with the earlier VIC20 computer became very productive Commodore 64 programmers and they found a strong and steady demand of specialized software in the area of special needs education. Actually many of the programmers trained themselves to become special needs education teachers. By the end of 80 s there was accumulated a remarkable collection of software in this area. The sound chip SID 6581 of Commodore 64 was excellent and a great amount of music has been composed using Commodore 64 computer as well.

The era of Commodore 64 in education became to a halt in practice when the PC machines with Microsoft operating system and Intel processor started to come to school computer labs at the end of 80s. They were reasonably priced and reasonably reliable. First of all an abundant collection of educational software was available and adequate for the schools to be used. It was relatively easy for technology oriented teachers to install new software, new operating system versions and new hardware to the computes. An educational network was easy to install as well. The PC labs became the standard in education and PCs have kept their leading position since then.

The common habit in Finland at the end of 80s became that one or two teachers of the school took over the responsibility to maintain the computer facilities of the schools. These pioneers became the ICT support teachers with a small financial compensation working 10 hours a week and receiving salary for one hour. They knew everything about the hardware and software and they were eager to help anybody who wanted to use computers in teaching. The computers were normally school's property and the computers were regularly updated and rebuilt when the ICT support teachers heard anything about new exciting innovations. In the 90s the municipal technology centres took over the responsibility of maintenance and the ICT support personnel devoted themselves to pedagogical support for the teachers and students.

By the 90s and thereafter all the schools have had a computer lab, and quite often some computers were installed in a public area of the school to enable the students to use the computers for educational or any other purposes. This concept has been successful because during breaks the students can find additional information about the day's topics, check their ideas, and prepare documents. The public area computers are used practically in every school and there are only a very few reports about stolen or damaged equipment.

The PC desktop computers have been the mainstream in the schools. A few schools adventured to try Sun's Java Station computers. The idea of a network computer was really ahead of time but it did not become a commercial success in USA and Sun Microsystems gave up developing Java Stations. The same lack of market enthusiasm applied to Newton by Apple or any other personal digital assistants.

The laptop computers never became important in the Finnish education mainly because of their weight, price, and vulnerability when carrying them from home to school and back. The schools do not want to purchase them because they are easy to steal and cumbersome to handle and distribute for classes. The tablet computers are much more promising for educational use. 


\section{Software}

In the 70 s there were great hopes that computers might bring a revolution to math education but the reality was that the early computers did not provide almost any tools or software for maths teaching. BASIC programming tools were only possible software for math teachers. On the contrary the language teachers got very soon used to effective ultra-behaviouristic language teaching software. The user interface in this software was simple. The students had to fill in missing words in a correct format and the software was suitably repeating the already learned concepts and producing more increasingly demanding sentences for the student to correct. It was also easy for the programmers to write software to check the answers from the student and calculate the percentage of right answers.

Some tentative maths programs had similar functionality but they were suitable only for the lower grades. However machine scored responses maintained their popularity because the feedback is immediate and clear. The learning result was to produce perfectly formulated correct sentences. Not so much attention was paid to produce meaningful communication using a foreign language. In 2010s it seems that the teachers have largely given up using educational software in language teaching in Finland and their idea is to create genuinely communicative situations in their classes using foreign languages.

VisiCalc and similar spreadsheet computer programs were popular among Apple users but the real educational use of spreadsheets started only when Microsoft Excel became available. The first popular word processor in the Finnish education was WordStar, and one generation of teachers started their computer user career by preparing their lessons and test papers using WordStar. The first massive in-service training sessions for teachers in the area of educational computing were organized in the end of 80 s to prepare teachers to use WordStar. This also indicates that maths and science teachers were not especially impressed on the prospects of using computers in science and maths classes.

The Public Domain software was very popular in Finland in 80s. Many teachers had a respectable collection of PD-software and in some cases they were producing their own applications. There were quite a few programming environments suitable for serious programming work especially Borland's Turbo Pascal and Turbo-C. That software became popular in schools and toward the end of 80s Turbo-Pascal had almost a monopoly in Finland. This also meant that the teachers and more advanced students were exchanging their software and at the same time learning new programming tricks.

\section{Networks}

First Finnish schools were furnished in the end of 70s with Mikro-Mikko computers and computer lab pedagogical networks from Nokia. As a pedagogical tool this lab network was not very successful. The main function was to provide a possibility for a teacher to follow students' progress. Teachers did not consider this possibility very 
useful because the students were quite irritated about this issue. The graphics in these computers was very primitive as well, and the computers were mostly used to fill simple checkbox forms for language learning or producing short essays.

Playing computer games became popular very fast and sometimes it was possible to connect computers in the lab for playing purposes. This was great fun at that time. Many students were active readers of the computer magazines and they learned to program their own simple game software. A great amount of this kind of software was distributed among students, and this network became the first real computer based social network in Finland. An important feature of this network was that it was not in any way regulated by any official body. Software piracy was quite common, and the first computer viruses came to the Finnish schools in the end of 80s simultaneously with the PCs occupying computer labs.

Packet-switched services became popular when X25 protocol in 1976 and X400 recommendations were publisher in 1984. Since then the Finnish schools have been connected electronically to the rest of the world. It became very popular for the students to chat with students in other countries. It was really exiting both for the students and the teachers to have chatting friends all over the world. Writing messages without seeing or hearing was the only means to communicate but still people felt that the world is now open for them.

The TCP/IP protocol reached its maturity by the end of 80 s and it enabled the vast expansion of electronic data exchange and especially the Internet. In 1988 Dr. Jarkko Oikarinen from Oulu, Finland created the messaging network IRC (Internet Relay Chat) which became immensely popular among young people. Practically all school students knew it and it became the first messaging system which teachers began to hate because so many students spent a substantial part of their free time in IRC in many cases at the expense of neglecting their homework.

The Internet reached the Finnish classrooms approximately in 1994. The first graphic browser ever was published in Finland in 1992 when four students at the Helsinki University of Technology wrote the Erwise browser. The students were Mr. Kim Nyberg, Mr. Teemu Rantanen, Ms. Kati Suominen and Mr. Kari Sydänmaanlakka It was designed for UNIX operating system but it did not gain any popularity afterwards. The first popular browser in Finland was Mosaic and it was widely used in the Finnish schools. For many years Mosaic and Netscape were the most popular browsers in the Finnish classrooms.

By the 2010s Internet connections are available in all the schools in Finland. This has been achieved thanks to the continuous funding from the government to build educational networks, furnish the computer labs, and most of all to train teachers to use teaching methods suitable in a computer intensive learning environment. A massive in-service training in the area of computers in education has been going for many years and it seems to bear fruits. The teachers feel themselves comfortable in social media and in electronic classroom communication. However they feel they are really uncomfortable with any special software. Even regular Microsoft Excel is difficult in spite of the fact that Microsoft Office has been the main working environment for the teachers for tens of years. 
Ubuntu Linux has gained some popularity, but the percentage of Linux users is relatively low. Earlier Linux implementations gave the impression of software which is suitable only for professionals. The municipal computer centres are really reluctant to make major changes in the municipal computer setup.

\section{Curricular Thinking}

At the end of $80 \mathrm{~s}$ the Finnish universities became interested in computers in education. Earlier almost the only activity in which to use a computer was programming. Gradually it became possible to communicate using the computer and at the same time an increasing amount of educational software became available for schools. This progress created interest in thinking about possibilities to implement computers in a more educational way into various subjects.

In late 80s some software developers became aware of the Market diagram model in creating educational software developed mainly in Norway. A remarkable amount of software came into Finnish educational software market at the end of $80 \mathrm{~s}$ using the Market diagram model. In spite of active marketing and clever ideas embedded in the applications the end users of the products considered them quite clumsy and noneducative, and the numbers sold were disappointing. In practice the earlier products which were based on traditional behavioristic approach sold better.

The Finnish National Board of Education (NBE) together with researchers at the Finnish universities took an initiative to find advanced methods of integrating computers in education. Starting from 1993 the NBE have launched and partly financed hundreds of school development programmes to innovate the best way to make computers and networks part of the classroom work. The title of the national programme was 'Finland towards the Information Society'. These projects have produced a massive amount of data for educational methods developers at the universities.

Professors Carl Bereiter and Marlene Scardamalia from the University of Toronto were the main contributors in introducing the concept of 'knowledge building'. The idea was enthusiastically accepted in Finland and many researchers at the universities abandoned the traditional behaviouristic view of learning. The Finnish government supported a number of research projects and in practice Finland entered the era of constructivism and later social constructivism in the beginning of 90s. The Finnish national curriculum framework from 1994 was following the new ideas and it brought a revolution to the Finnish curriculum thinking. Finland has been evaluated highly in the OECD Programme for International Student Assessment (PISA) for many years, and the foundation for this success was laid in this particular framework curriculum and its implementation.

This idea had unfortunately a seed for disaster because programming, learning to use computer applications, and computer hardware skills were declared obsolete. It was officially declared that the students will learn the computer skills while they are using computers as tools, and no additional subject 'computer science' was needed in the schools. The immediate consequence of that policy was that the Finnish 
universities downgraded their teacher training master programmes in computer science, and the universities ceased to produce formally qualified computer science teachers to the Finnish comprehensive and upper secondary education. The latter part of the Finnish education system is comparable to the sixth form education in England.

The leading concept in the new thinking was that by retrieving information from the Internet and creating essays using that information will give a deep insight for the students in utilizing computers. Afterwards it became obvious that this assumption is not correct and the computer skills of the Finnish students did not develop as expected.

The Finnish National Curriculum Framework in 2004 was heavily leaning on social constructivist ideas and this significantly enforcing the role of computers in education in Finland. It became essential to use computers and computer networks as a constructivist learning tool. Unfortunately the initiative of having computer science as a subject with nationally defined learning contents was abandoned.

\section{The Future}

ICT has been deeply integrating into everyday work in schools. The school administration is completely dependent on extensive databases containing all necessary data on students, teachers, schedules, classrooms, school financing and document management.

The classes are becoming more active and more interesting to students. Information from many sources is always available, and the students learn to be critical when forming their attitudes and opinions. Many classical conventions like the concept of a classroom or a school will become obsolete. Everything can be made virtual.

There have been discussions about ubiquitous ICT which in practice means more digital services but also enables more possibilities to monitor and control all the persons and their activities in the school community. It is highly possible that this is not only a positive feature. A school community is exceptionally sensitive in social relations because there are a large number children or teenage students. Excessive control indicates that the students are expected to resemble more robots than human beings.

Hopefully the future school will use ICT in a way which is respecting students as valuable and individual human beings having their own aspirations and dreams worth being fulfilled. 